DOI: http://dx.doi.org/10.20435/1430

\title{
0 embelezamento das cidades sob a ótica da iluminação urbana em fachadas e monumentos históricos
}

\section{The beautification of the cities from the perspective of urban lighting on facades and monuments}

Natacha Oliskovicz ${ }^{1}$

${ }^{1}$ Mestre em Desenvolvimento Local (UCDB), Pós-Graduada em Iluminação e Design de Interiores (UCB), Graduada em Arquitetura e Urbanismo (UNIDERP). Atualmente é Coordenadora e Professora do Curso Superior em Tecnologia de Design em Interiores do Centro Universitário Anhanguera. E-mail: natacha.oliskovicz@hotmail.com 


\section{RESUMO}

A iluminação urbana passa por vários processos adaptando-se à realidade encontrada atualmente. Antes vista como apenas iluminação pública, hoje a iluminação urbana sugere um conceito mais amplo, pois diz respeito à segurança, ao embelezamento das cidades durante o período noturno. Faz então provocar uma reflexão sobre o tema e no papel que a luz pode desempenhar na identificação e valorização de edifícios históricos. A pesquisa tem, como objetivo geral, pesquisar a iluminação urbana aplicada dentro dos projeto urbanos sob a ótica da iluminação em fachadas e monumentos históricos. Para o desenvolvimento da pesquisa, foi feito um embasamento teórico do trabalho utilizando a revisão bibliográfica e análise de produções científicas relacionadas ao tema. Dessa forma, vale ressaltar, que a luz revela a beleza do cenário urbano noturno, proporcionando efeitos e percepções visuais diferentes daqueles observados durante $o$ dia, resultando em cidades mais atrativas e convidativas aos visitantes e turistas.

\section{ABSTRACT}

Urban lighting goes through various processes adapting to reality found today. Before seen as only streetlights today urban lighting suggests a broader concept as it relates to safety, beautification of cities during the night. then make provoke a reflection on the subject and the role that light can play in identifying and recovery of historic buildings. The research has the general objective, search the urban lighting applied in urban design from the perspective of lighting facades and historical monuments. For the development of research a theoretical basis of the work was done using the literature review and analysis of scientific publications related to the theme. Thus, it is noteworthy that the light reveals the beauty of the night urban setting, providing different effects and visual perceptions from those observed during the day, resulting in more attractive and inviting cities to visitors and tourists.

\section{KEY WORDS}

$\begin{aligned} \text { iluminação urbana } & \text { urban lighting } \\ \text { cidades } & \text { cities } \\ \text { edifícios históricos } & \text { buildings history }\end{aligned}$




\section{INTRODUÇÃo}

Por meio do desenvolvimento e da forma como se aplica a iluminação urbana, as cidades podem sugerir diferentes sensações visuais e hierarquias, sendo elas percebidas pela população. A iluminação urbana vem se adaptando à realidade encontrada atualmente. Antes vista apenas como iluminação pública, hoje a iluminação urbana sugere um conceito mais amplo, pois diz respeito à segurança e ao embelezamento das cidades durante o período noturno.

A falta de profissionais especializados encarregados de projetar e sugerir uma iluminação urbana com qualidade faz com que a população perca o interesse pelos monumentos significativos de uma cidade e consequentemente pela sua história.

A pesquisa tem, como objetivo geral, pesquisar a iluminação urbana aplicada dentro dos projetos urbanos sob a ótica da iluminação em fachadas e monumentos históricos. A iluminação de fachada, além de valorizar os aspectos arquitetônicos e históricos do edifício, contribui para maior segurança noturna dos espaços das cidades. Porém, ao iluminar monumentos históricos e prédios tombados pelo Instituto de Patrimônio Histórico e Artístico Nacional (IPHAN), a iluminação torna-se definitivamente arte pura, pois além de lidar com a luz deve-se entender o valor artístico de cada prédio e de cada monumento. Por isso trabalhar com a luz inclui conhecimento acumulado por meio de experiências prévias do cotidiano.

Assim o lighting designer (profissional da luz) já domina essas experiências e usa a luz como um elemento de aplicação, incorporando o sentimento e a emoção. A atividade criativa desse profissional está, portanto, permanentemente guiada pela consciência de que ele estará trabalhando sobre a obra de outro artista, não esquecendo que a luz não é mais importante que a obra iluminada. 
A luz é um fenômeno virtual, um meio maleável que sensibiliza a atmosfera e os lugares, com ela é possível revestir uma superfície ou até mesmo pintar sem tinta. A luz é um elemento que unifica e diferencia espaços, criando um foco, desenvolvendo uma hierarquia, proporcionando movimento, padrões e ritmos em uma cidade, e provocar esse efeito é tão rápido quanto atenuá-lo, ou até retirá-lo.

Faz-se necessário uma reflexão sobre a função que a luz pode desempenhar na identificação e valorização desses edifícios históricos. Toda cidade tem sua vocação e características específicas, conhecer sua identidade, sua estrutura e seu significado é planejar, de forma valorizada, a imagem da cidade.

\section{PATRIMÔNIO HISTÓRICO E CULTURAL}

0 embelezamento das cidades e principalmente o desenvolvimento tecnológico de equipamentos de iluminação vêm possibilitando a valorização de marcos e monumentos históricos. Os patrimônios históricos e culturais estão protegido pelo IPHAN, que é uma autarquia federal vinculada ao Ministério da Cultura, cuja responsabilidade é de preservar os diferentes elementos que compõem a sociedade brasileira.

O IPHAN (s.d.) tem como missão promover e coordenar o processo de preservação do Patrimônio Cultural Brasileiro para fortalecer as identidades, garantindo o direito à memória e contribuindo para o desenvolvimento socioeconômico do Brasil, tendo como responsabilidade, preservar, divulgar e fiscalizar os bens culturais, bem como assegurar a permanência e usufruto desses bens para a atual e as futuras gerações.

A Constituição Brasileira também estabelece que cabe ao poder público, isto é, União, Estados e Municípios, com o apoio da comunidade, a proteção, preservação e gestão do patrimônio cultural do país (IPHAN, s.d.). 
De acordo com a classificação da Organização das Nações Unidas para a Ciência e a Cultura (UNESCO), Patrimônios Culturais são obras de arquitetura, escultura e pintura monumentais ou de caráter arqueológico, de valor universal, excepcional do ponto de vista da história, da arte ou da ciência, e ainda obras isoladas ou conjugadas do homem e da natureza, de significativo valor histórico, estético, etnológico ou antropológico (PORTAL BRASIL, 2009).

Conforme o próprio IPHAN (s.d.), os patrimonios culturais estão divididos da seguinte forma: Patrimônio Material, Patrimônio Mundial e Patrimônio Imaterial. Neste estudo, serão abordados somente conceitos de iluminação utilizados nos Patrimônios Material e Mundial:

- Patrimônio Material: com base em legislações específicas, é composto por um conjunto de bens culturais classificados segundo sua natureza nos quatro Livros do Tombo: arqueológico, paisagístico e etnográfico; histórico; belas artes; e das artes aplicadas. Eles estão divididos em bens imóveis como os núcleos urbanos, sítios arqueológicos e paisagísticos e bens individuais; e móveis como coleções arqueológicas, acervos museológicos, documentais, bibliográficos, arquivísticos, videográficos, fotográficos e cinematográficos.

- Patrimônio Mundial: a Convenção do Patrimônio Mundial, criada em 1972 pela UNESCO, tem como objetivo incentivar a preservação de bens culturais e naturais considerados significativos para a humanidade. Trata-se de um esforço internacional de valorização de bens que, por sua importância como referência e identidade das nações, possam ser considerados patrimônio de todos os povos. Cabe aos países signatários dessa convenção indicarem bens culturais e naturais a serem inscritos na Lista do Patrimônio Mundial. Mas não só de aspectos físicos se constitui a cultura de um povo. Existem também as tradições, o folclore, os saberes, as línguas, as festas, transmitidos oral ou gestualmente. 
Barreto (2004), destaca que o IPHAN possui grandes atribuições ligadas a ações de identificação, proteção, promoção, restauração, prevenção e fiscalização de bens físicos quanto à administração de bibliotecas, arquivos e museus, sempre com objetivo cultural brasileiro. Asim "os trabalhos de preservação de bens culturais é extremamente complexo e demanda conhecimento científico, fundamentação histórica e sensibilidade estética" (BARRETO, 2004, p. 7).

\section{PLANO DIRETOR DE ILUMINAÇÃO}

As cidades sugerem diferentes sensações visuais, sendo assim, a iluminação urbana é um importante componente dos projetos das prefeituras relacionados ao embelezamento das cidades. Godoy (2003) assinala que a imagem do meio urbano pode ser analisada, considerando-se os seus três componentes principais: identidade, estrutura e significado.

Essas intervenções urbanas relacionadas com a iluminação ganham forças no contexto da valorização tanto dos espaços como de monumentos e prédios históricos, inspirando respeito, admiração e orgulho aos cidadões (JUNQUEIRA; YUNES, 2013).

Nesse contexto, o Plano Diretor de Iluminação de uma cidade deve contemplar diversas análises e elementos que caracterizam os aspectos urbanos. Na ótica de Godoy (2003), esse plano deve levar em consideração vários fatores como: caminhos, limites, zonas, nós e marcos.

Godoy (2003) destaca, de forma contundente, o que cada fator determina:

$\checkmark$ Caminhos: canais pelo qual a população se desloca, podendo ser avenidas, ruas, alamedas, passeios, calçadões, estradas etc.

$\checkmark$ Limites: elementos lineares que definem as bordas fisicas de observação, podendo ser as estradas, rios, linhas férreas, muros etc, dando às pessoas referências laterais. 
$\checkmark$ Zonas: são grandes áreas, onde as pessoas podem identificar características diferenciasdas, reconhecendo-as por meio de referências urbanas, topográficas, edifícios históricos ou monumentos, igrejas, templos etc.

$\checkmark$ Nós: pontos específicos, estratégicamente localizados, considerados como pontos de referências, podendo ser criados pela concentração ou cruzamentos de caminhos importantes no contexto de uma cidade.

$\checkmark$ Marcos: referências externas, emblemáticas das cidades, constituidas por edificios, monumentos, elementos da natureza ou acidentes geográficos. Podem também ser usados como elementos de referências.

Além desses fatores, vale ressaltar também a imporância da segurança, eficiência energética e transformações decorrentes de intervenções realizadas pelo poder público. Sendo assim, o Plano Diretor é fundamental para a criação das condições de uso de uma cidade sob diferentes pontos de vista, tornando importante para o desenvolvimento das políticas de iluminação urbana, compostas pela gestão da iluminação pública e de possíveis intervenções a serem realizadas. Para o Lighting Designer Graham Phoenix (2006, p. 10):

O Plano Diretor de Iluminação deve estar no topo das decisões estratégicas, no topo da hierarquia da luz. Deve definir o que se deseja atingir em termos de luz nos diferentes ambientes urbanos. Deve proporcionar parâmetros para designers e engenheiros trabalharem em conjunto e em paralelo, buscando um objetivo comum.

Ou seja, todos os envolvidos devem trabalhar em harmonia para que o resultado final seja satisfatório, incluindo a população, que de fato é quem irá desfrutar desse projeto. Em termos gerais, o Plano Diretor de Iluminação para uma cidade deve analisá-la por completo, suas características básicas, identificar as regiões ou áreas que a tornam mais atrativa durante o período noturno e, 
para alcançar esse resultado final, é necessário dividir por etapas:

- Contexto Global: análise da imagem, fluxos, nós internos, rotas de aproximação, topografia, clima, sazonalidade, elementos aquáticos, verdes, características arquitetônicas, histórias, ponto de visão e iluminação existente.

- Análise das Zonas: nessa etapa, todos os fatores relacionados acima, devem ser analisados em detalhes do ponto de vista da iluminação examinados separadamente. As zonas, referem-se às formas: históricas, industriais, comerciais, residenciais e parques. A análise individual desses fatores deve ter: função, significado histórico, aparência, imagem, simbolismo, características arquitetônicas, mérito artístico, visão pelo todo, efeitos na silhueta urbana, direções, perspectivas, distâncias, facilidade de reconhecimento, formas, dimensões e cores.

Um estudo minucioso deve ser realizado, para poder chegar a uma conclusão e poder desenvolver um excelente Plano Diretor de Iluminação.

- Diretrizes: nessa última etapa, definem-se as diretrizes e determinam-se os critérios pertinentes aos projetos a serem considerados.

No Brasil, grande parte dos projetos de iluminação das cidades são, geralmente, desenvolvidos pelo Poder Público, que tem como objetivo o menor investimento e condições mínimas de utilização. É necessário, portanto, compreender o papel atribuído à iluminação no processo de planejamento, considerando seus aspectos técnicos e outros ligados à valorização da paisagem urbana e à qualidade visual da cidade contemporânea que apresenta, mais do que nunca, a sua imagem (JUNQUEIRA; YUNES, 2013).

É interessante considerar, sempre que possível, as referências diurnas para os objetivos específicos noturnos, ou seja, são complementares entre si. Muitas vezes, estão relacionados com as mesmas características: percepção, valorização, expressão, visão 
turística e segurança. Sendo assim, a preparação de um Plano Diretor de iluminação de uma cidade depende dos vários cenários analisados, sem que se esqueça de usar a iluminação como uma ferramenta artística e técnica ao mesmo tempo. Só assim se poderá ter uma iluminação adequada para a valorização dos patrimônios históricos de uma cidade.

\section{ILUMINAÇÃO PÚBLICA}

A iluminação pública faz parte dos projetos de iluminação urbana e, até poucos anos atrás, era tratada simplesmente por questões políticas, sendo assim, não recebia a devida atenção, ocasionando em grande parte um descuido nessa área. Tudo se baseava em quantidade de luz, e não em qualidade de luz, como se pode observar atualmente em muitas cidades brasileiras.

A iluminação pública consiste em considerar importantes questões relacionadas ao urbanismo, como a arquitetura, a estética e principalmente o bem-estar da comunidade; integrando todos esses elementos em harmonia, tem-se um excelente desenvolvimento para uma cidade.

Atualmente os projetos de iluminação pública estão se voltando para o embelezamento das cidades, e essa mudança deve vir de uma boa base sólida, ou seja, de um plano diretor direcionado à iluminação, realidade essa de que nem todas as cidades dispõem ainda.

Deve-se levar em conta que hoje existem grandes profissionais diretamente ligados a essas questões, e isso sem dúvida deve permanecer. A iluminação pública é um grande agente criador de diversos ambientes, principalmente em se tratando de espaços urbanos noturnos.

As questões relacionadas à quantidade de luz está diretamente ligada à eficiência e ao rendimento luminoso. Por exemplo, a fonte de luz (lâmpada), por sua vez produz lumens, e esses lumens 
estão relacionados aos watts de consumo, a sua durabilidade, elementos até então mais importante, pois o que tinhamos até então era suficiente para iluminar as vias de tráfego. Hoje os projetos de iluminação pública querem proporcionar mais do isso, querem juntar quantidade de luz com qualidade, em que entram fatores como reprodução de cor e temperatura de cor, características técnicas que as fontes de luz também emitem.

Szabo (2003, p. 9) também acredita e afirma que:

Geralmente as pessoas acham que basta resolver as questões quantitativas. Não é verdade. Nós, evidentemente, temos que ver sempre o aspecto quantitativo - fluxo luminoso que vai gerar uma iluminância em lux - mas temos que dar o mesmo valor ao aspecto qualitativo, uma das minhas paixões, que é a temperatura de cor e índice de reprodução de cor. Temperatura de cor é um dos grandes segredos de um bom projeto de iluminação.

José Canosa Miguez (LUME ARQUITETURA, 2003/2004) pensa da mesma forma e vem tratando justamente sobre isso, em proporcionar uma iluminação pública que trabalhe com ambas funções, fazendo com que uma complemente a outra.

\section{ILUMINAÇÃO URBANA}

A iluminação urbana é percebida históricamente por meio de seu desenvolvimento a partir do século XIX, gerando mudanças nos hábitos e costumes da população dos centros urbano.

[...] pode-seobservar trêsépocas bastante distintasnoqueserefereao pensamento da iluminação pública: até a invenção da energia elétrica, a iluminação pública tinha o sentido de transmitir exclusivamente segurança; do fim do século XIX até os anos 80 do século XX, a iluminação pública tinha sentido funcional e foi basicamente pensada para o trânsito veicular. No final do último século passou a ser encarada como fator de valorização da paisagem urbana, tornando-se um componente importante do movimento de marketing das cidades, como criadora de identidade do espaço urbano. (SANTOS, 2005, p. 32). 
Os urbanistas projetam cidades diurnas, organizam e distribuem da melhor maneira a movimentação e o crescimento dos centros urbanos; entretanto, quando chega o momento de projetar a iluminação noturna, momento esse de pensar em todas as possibilidades que um bom projeto de iluminação urbana pode proporcionar para essa cidade, para dar continuidade a esse crescimento e desenvolvimento, simplesmente não dão a devida atenção. Aplicam um desenho em cima do projeto urbano diurno e distribuem de maneira uniforme os pontos de luz.

É preciso distinguir as ações e atividades realizadas durante o dia e a possibilidade de ações que podem ser feitas à noite em uma cidade. José Canosa Miguez (LUME ARQUITETURA, 2003/2004) afirma que a iluminação de uma cidade é, na realidade, o resultado de três fontes geradoras, sendo elas: a luz da mídia, a luz da arquitetura e aquela luz existente nas vias e espaços público. 0 mesmo autor finaliza levantando a importância de considerar e, sempre que possível, tirar partido de todas as potencialidades da luz: como criadora de inusitadas cenografias urbanas, como ativa portadora de símbolos, como importante agente sinalético e festivo e, principalmente, psicológico.

Junqueira e Yunes (2013), assinalam que essa imagem da cidade contemporânea pode ser analisada sob diferentes pontos de vista. São duas as análises mais recorrentes que, não raro, se confundem: o movimento de origem francesa L'Urbanisme Lumiére e o já global City Beautification.

$\checkmark$ L'Urbanisme Lumiére: metodologia de iluminação urbana mais utilizada na Europa, cuja definição é dada por Narboni (2003, p. 223) como sendo "a área da atividade de iluminação urbana que trata da planificação da iluminação à escala regional, do aglomerado de população, cidade ou aldeia, ou do local a privilegiar".

Este conceito tem como característica o planejamento luminotécnico de áreas de grande escala, por meio de uma concepção 
multidisciplinar que resulta no desenvolvimento de um plano diretor de iluminação (JUNQUEIRA; YUNES, 2013).

$\checkmark$ O City Beautification aposta no embelezamento de cidades para modificar a atitude dos usuários, aumentando a segurança, diminuindo a degradação dos espaços públicos, reduzindo ações de vandalismo sobre a arquitetura e, por fim, no uso funcional durante a noite. Sua percepção tanto dos espaços, e tudo que a envolve como volumes, estruturas, enfim os aspectos do urbanismo relacionado com o ambiente noturno. Identificam que as características das intervenções urbanas produzem benefícios relacionado com o destaque e a valorização histórica, cultural, social e economica das cidades.

Moisinho (2010) define que o City Beautification, quando introduzido nas cidades, pode ser qualquer intervenção que cause a melhoria visual de um segmento urbano.

Conforme Godoy (2003, p. 23), o embelezamento de cidades é uma abordagem integrada considerando:

Funcionalidade do sistema de iluminação (tais como níveis de iluminância, uniformidade e ofuscamento); efeitos estéticos e emocionais; tridimensão do cenário urbano, sua arquitetura, massa e formas; iluminação dos espaços púplicos que canalizam os movimentos de veiculos e pedestres, e os espaços para os quais os mesmos são direcionados; iluminação para sinalização; paisagismo (o chamado Landscape Lighting, que contempla a valorização dos recursos naturais ou elementos construídos pelo homem, tais como parques, jardins, árvores e áreas verdes em geral); valorização dos espaços urbanos da iluminação funcional e decorativa de vias de tráfego de pedestres, zonas de comércio, calçadões etc; iluminação festiva e de entretenimento em datas específicas; iluminação para publicidade e iluminação conjugada ao mobiliário urbano.

No Brasil, seu princípio está fortemente atrelado à ideia de embelezamento da cidade via de destaque pontual de monumentos arquitetônicos. De forma geral, seus princípios visam 
implementar o embelezamento da cidade por meio de intervenções isoladas e analisando sua composição formal como forma de expressão artística sem, necessariamente, ter um embasamento social (JUNQUEIRA; YUNES, 2013).

Sendo assim, outro equívoco é relacionar o termo City Beautification, conceito de intervenção luminotécnica, com o City Beautiful, movimento de valorização da cidade e reestruturação urbana, com intervenções construtivas. São, no entanto, dois conceitos distintos, pois L'Urbanisme Lumière é mais profundo que isso, cuidando das funções e das formas que as pessoas usam nas cidades.

Essas mudanças e intervenções, se não forem bem planejadas, podem levar a uma outra forma de produção do espaço urbano, a de transformar as cidades em espetáculos, perseguidas por gestores que querem apenas mascarar a realidade das cidades, camuflandos e desviando determinados problemas, conhecidas como estratégias de city marketing. Nasce, dessa forma, uma arquitetura de espetáculo para encenar lugares públicos, uma teatralização da vida pública, via arquitetura cenográfica utilizada como estratégia para atrair investimentos internacionais para o local que sofre a transformação cênica (JUNQUEIRA; YUNES, 2013).

A redescoberta do convívio e vizinhança, como reação aos preceitos mecanicistas do modernismo, trouxe o conceito de ambiência e valorização da paisagem urbana. Assim, a criação de uma identidade noturna valoriza o patrimônio cultural e natural das cidad es e agrega diferentes segmentos da sociedade em torno de um objetivo comum. (SANTOS, 2005, p. 87).

Assim, a iluminação urbana e arquitetural adequada permite que habitantes, inclusive turistas, sintam-se mais seguros pelas cidades, facilitando a locomoção e a orientação no período noturno da cidade. 


\section{ILUMINAÇÃO DE FACHADAS E MONUMENTOS}

Apenas a luz revela a beleza do cenário urbano; sem ela, prédios e monumentos podem passar despercebidos, ou, por outro lado, tornarem referência e até mesmo ponto turístico. Conforme Neide Senzi (CARVALHO, 2003), a iluminação de fachadas pode agregar valor tanto para edifícios públicos como privados, pelo simples fato de atrair os olhares, despertar curiosidades e a valorização deles.

Godoy (2003) menciona que a iluminação de fachadas e monumentos proporciona qualidade de vida, pois a relacionamos com a segurança das pessoas, preservação do patrimônio histórico e cultural, proteção ao meio ambiente, interação social, promoção do turismo, visibilidade das ações tanto do poder público como privado e atração de investimentos e estímulos às atividades comerciais e de lazer para uma cidade. Assim:

Durante o dia, a cidade e seus edifícios são iluminados pela luz solar direta e pela luz indireta e difusa do céu, ou por ambas ao mesmo tempo, mudando constantemente a direção, a cor e as relações de luz e sombra. Esses mesmos volumes iluminados com luz artificial contrastam-se com a escuridão da noite, tornando-se dramaticamente destacados e belos. (GODOY, 2003, p. 24).

José Canosa Miguez (LUME ARQUITETURA, 2003, p. 56) diferencia a iluminação natural da artificial em monumentos e fachadas da seguinte forma: "a luz do sol envolve e o integra ao seu ambiente. A iluminação artificial, ao contrário, é restritiva, diferencia e destaca um monumento do seu entorno, muitas vezes isolando-o de seu contexto urbano". Já Neide Senzi (CARVALHO, 2003), também se refere a esse respeito assinalando que a iluminação artificial deve ser considerada como contraponto da iluminação natural, ou seja, se a iluminação natural é caracterizada pela uniformidade, indefinição de volumes ou sombreamento indesejável, a iluminação artificial deve proporcionar contraste e exaltar a volumetria de um edifício. 
José Canosa Miguez (LUME ARQUITETURA, 2003) também ressalta que a luz deve considerar a responsabilidade em preservar a identidade dos cenários naturais e dos monumentos que outros homens conceberam e construíram. Para construções mais recentes, existe a possibilidade de se dialogar com o arquiteto, trocar ideias e informações; mas, quando não é possível, a sensibilidade do projetista faz a diferença na hora de valorizar uma obra. José Canosa Miguez (LUME ARQUITETURA, 2003, p. 58) finaliza explicando que existem duas diferentes expressões de se iluminar fachadas e monumentos, dos quais o projetista irá partir para seu conceito de projeto:

- Illumination: define a iluminação com expressão clássica, ultrapassada (sentido depreciativo). Designa os projetos de luz calcados na abordagem que busca uma cópia da imagem diurna do monumento.

- Mettre em lumiere: é o ato de iluminar como expressão artística, evidenciar, destacar, valorizar pela luz. [...] traduz uma intenção e a visão sensível do criador.

Neide Senzi (CARVALHO, 2003) complementa que em seus projetos o primeiro item a ser analisado no desenvolvimento de um projeto de iluminação de uma fachada é seu estilo arquitetônico, e que particularmente segue a escola francesa (mettre em lumiere), ou seja, determina a valorização e interpretação dos principais pontos da arquitetura; embora fachadas sejam superfícies grandes, sua iluminação deve ser pensada de forma micro, respeitando os detalhes, ornamentos e volumes, trabalhando pontualmente para que no conjunto se crie um conceito tridimensional.

\section{TECNOLOGIA E EQUIPAMENTOS}

No aporte de Godoy (2003), as despesas com o consumo de energia de um sistema de iluminação dependem da forma como este é projetado e, consequentemente, das escolhas da tecnologia 
e dos equipamentos. Existem dois fatores que influenciam nesse consumo de energia: a seleção dos tipos e quantidades de elementos a serem iluminados por região da cidade, sem produção desnecessária de luz, e a determinação da distribuição adequada das luminâncias para a apreciação do elemento iluminado e do seu entorno, com níveis mínimos e máximos pré-estabelecidos.

Existem no mercado atualmente vários tipos de fontes de luz para trabalhar dentro dos projetos de iluminação, entretanto uma não é melhor que a outra, cada uma tem a sua função dentro de cada projeto, pois umas ganham na durabilidade, outras no índice de reprodução de cor, na temperatura de cor e em tantas outras características que as diferenciam.

Até pouco tempo atrás, trabalhava-se nos projetos de iluminação de fachadas e monumentos com dois tipos de lâmpadas, vapor de sódio (luz amarela) e vapor metálico (luz branca). Hoje o LED vem ganhando destaque por proporcionar não só essas duas cores na mesma fonte de luz, mas uma infinita possibilidade de cores, via sistema RGB, que vem a ser a dimerização do vermelho (red), verde (green) e azul (blue) conhecidas como cores primárias da luz.

A aplicação do LED em projetos de iluminação arquitetônica vem oferecendo inúmeras vantagens como: longa durabilidade (eliminando a necessidade de manutenção constante), trabalho em baixa tensão (sendo mais seguros); temperatura de cor e o índice de reprodução de cor também são obstáculos que vêm sendo vencidos a cada ano. Outra grande vantagem, por serem pequenos, sua luz é quase puntiforme facilitando tanto na instalação quanto no controle de luz emitida. Em prédios e monumentos tombados pelo patrimônio histórico, as intervenções são limitadas pela necessidade de preservação das características construtivas originais da edificação.

Os LEDs vêm atendendo a uma grande quantidade de projetos, como praças, avenidas, fachadas e monumentos e em todo 
lugar onde se queira valorizar elementos artísticos. As lâmpadas vapor de sódio e vapor metálico, podem parecer ser um problema em determinados projetos, porque são lâmpadas que, se houver um pico de luz ou algo que as apague, elas demoram para acender. Lugares com grandes monumentos, pontos turísticos de grande destaque ou que têm visitação noturna, não podem ficar apagados em hipótese alguma, por isso, o LED vem substituindo essas fontes de luz, pois seu acendimento é imediato.

Quanto às luminárias, estas possuem a função de proteger as lâmpadas e equipamentos auxiliares contra danos provocados pela ação das intempéries e choques mecânicos. São projetadas para controlar o fluxo luminoso das lâmpadas sem proporcionar ofuscamento e desperdício (grande responsável pela poluição luminosa), sendo essa escolha fundamental para um projeto de eficiência luminosa. Silva (2009) comenta que na atualidade pode-se encontrar uma enorme variedade de luminárias e equipamentos que oferecem diversas CDL (curva de distribuição luminosa) para atender a diferentes situações. Entretanto deve-se lembrar que a escolha do material e especificação dos equipamentos é fundamental ao projeto, pois o espaço público onde estão inseridos os projetos de iluminação de fachadas e monumentos também estão sujeitos as agressões de vandalismo. Quanto aos equipamentos com LED, encontram-se várias opções, proporcionando sistemas lineares, módulos redondos, quadrados, spots e infinitas possibilidades de aplicação tato estética quanto técnica.

\section{DESAFIOS DE PROJETOS}

Existem critérios e desafios para desenvolver um projeto de iluminação em fachadas e monumentos tombados. Barreto (2004) afirma que o IPHAN observa alguns parâmetros para a aprovação de projetos de iluminação levando em conta dois pontos de vista: a iluminação interna e a iluminação externa. 
Barretos (2004) salienta que, para a iluminação externa, existem considerações e conceitos mais próximos da intervenção urbana, a saber:

1 - A proposta luminotécnica deve levar em consideração as caracteríticas construtivas e espaciais da edificação, evidenciando suas linhas arquitetonicas mais marcantes ou definidoras do estilo a que pertence.

2 - 0 destaque em relação ao entorno não deve prejudicar a leitura do contexto urbanístico em que se insere a edificação.

3 - 0 uso de fontes artificiais de luz com baixa reprodução de cores, equipamentos dotados de filtros de cores ou lâmpadas coloridas, na iluminação externa de monumentos, deve ser precedido de cuidadoso estudo, visto que, no geral, essa intervenção não é adequada. Quando dos trabalhos de restauração de uma edificação, uma etapa importante é a prospecção das cores originais, tanto de interiores quanto de fachadas, de modo a conseguir a composição cromática original idealizadora pelo projetista ou executor. Assim, da mesma forma que o arquiteto restaurador incorre em erro, ao não levar esse dado em consideração na definição das cores da edificação, também será inadequada uma intervenção luminotécnica que, diante de uma composição de cores importante, para o entendimento ou resgate de seu estilo arquitetônico, descaracterize-a pela utilização inadequada de cores. Esse posicionamento não significa que a utilização de cores será sempre vetada para essas edificações, poderá ser aceita, por exemplo, durante eventos ou festejos.

4 -A instalação de equipamentos não deve causar danos à edificação ou demasiado impacto visual no período noturno, sempre com o objetivo de valorizar a edificação, minimizando o impacto da poluição visual.

5 - Pautar o projeto na possibilidade de manutenção, prevendo fontes de luz artificial eficiente com elevada eficiência energética e durabilidade. 
Deve-se sempre preservar o acervo e respeitar os níveis de iluminaçào recomendados por normas internacionais e nacionais. Esses níveis de iluminação recomendados para cada material são estipulados em tabelas específicas. Pode-se identificar que há acervos que utilizam uma dosagem de unidade lux X hora/ano.

Existem estudos sobre essa unidade de medição, pois aparelhos mais modernos já apresentam valores em $\mathrm{mW} / \mathrm{cm}^{2}$, ou seja, microwatts por centímetro quadrado. Sendo uma avaliação mais precisa por se tratar da radiação efetivamente incidente sobre o acervo. Portanto a análise de projetos submetidos ao IPHAN fundamenta-se nos critérios acima mensionados. Por outro lado, devem ser solicitados memorial descritivo e memória de cálculo que comprovem a correção da proposta de iluminação e sua adequação às premissas técnicas estabelecidas.

\section{POLUIÇÃO LUMINOSA}

Relacionada diretamente com os cuidados ambientais, deve-se ter atenção dupla ao se elaborar um projeto de iluminação para fachadas e monumentos. A primeira está relacionada à escolha da fonte de luz (lâmpada), pois pode alterar o ecossistema local, porque algumas lâmpadas têm características de atrairem os insetos. Atualmente pode-se evitar esse impacto, pois existe a possibilidade de reduzir a emissão do ultravioleta que as lâmpadas emitem, utilizando-se filtros. A segunda atenção está relacionada com a poluição luminosa, ou seja, o excesso ou o desperdício de luz. O IDA (International Dark Sky Association ) afirma que uma grande parte das luminárias ainda fabricadas não possuem controle ótico eficiente que evitem esse desperdício, provocando a chamada luz invasora, penetrando pelas janelas e perturbando seriamente a visão noturna que se tem do céu. Essa luz produzida e desperdiçada é enviada para o espaço e já chega junto com aproximadamente a metade de toda a iluminação produzida no planeta. 
Vários fatores negativos estão relacionado com esse desperdício sendo eles: ofuscamento, luz invasora, dificuldade de observação astronômica, efeitos na população, efeitos no sistema de transporte e principalmente efeitos em plantas e animais. Em todo projeto de iluminação urbana ou para fachadas e monumentos, de forma mais específica, deve-se utilizar somente a quantidade de luz necessária e suficiente para cada aplicação, na utilização de sistemas que não prejudiquem a visão noturna, na eliminação do ofuscamento e no controle do fluxo luminoso em função da aplicação, do local e do período noturno.

\section{CONSIDERAÇõES FINAIS}

A iluminação urbana vem ganhando força no contexto da valorização dos espaços e monumentos, inspirando respeito, admiração e orgulho aos cidadãos, porém precisam que seus níveis de iluminância sejam repensados, porque foram definidos em função do automóvel, há anos, e não em função da realidade das cidades de hoje.

0 que se pode observar atualmente é que as cidades estão se voltando para a preocupação da vida noturna de suas atividade, estão tendo destaque em vários aspectos, pois estão proporcionando a integração das ambiências diurnas com as noturnas, repensando no enfoque do homem que habita e busca uma melhor integração com a arquitetura o urbanismo.

Existem ainda vários fatores que freiam esse desenvolvimento, porém o embelezamento das cidades é uma ferramenta poderosa no sentido da valorização entre a cidade e seus moradores, aliando aspectos arquitetônicos e culturais com segurança. A luz revela a beleza do cenário urbano noturno, proporcionando efeitos e percepções visuais diferentes daqueles observados durante o dia, resultando em cidades mais atrativas e convidativas aos visitantes e turista. 


\section{REFERÊNCIAS}

BARRETO, Leonardo. Patrimônio histórico: preservando com conhecimento e respeito. Lume Arquitetura, São Paulo, ed. 9, ago./set. 2004. Entrevista concedida a Cláudia Carvalho. Disponível em: <http:// www.lumearquitetura.com.br/pdf/ed09/ed_09_Entrevista.pdf>.

CARVALHO, Cláudia. Fachadas que valorizam - iluminação "micro" em escala "macro". Lume Arquitetura, São Paulo, ed. 03, ago./set. 2003. Seção Case. Disponível em: <http://www.lumearquitetura.com.br/pdf/ed03/ ed_03_Case_Fachadas.pdf $>$.

GODOY, Plinio. City bealtifufication - iluminação para o embelezamento das cidades. Lume Arquitetura, São Paulo, ed. 4, out./nov. 2003. Seção Ponto de Vista. Disponível em: <http://www.lumearquitetura.com.br/ pdf/ed04/ed_04_Ponto.pdf>.

INSTITUTO DE PATRIMÔNIO HISTÓRICO E ARTÍSTICO NACIONAL (IPHAN). [s.d.]. Diponível em: <http://portal.iphan.gov.br/>. Acesso em: 20 mar. 2015.

JUNQEIRA, Mariana; YUNES, Gilberto S. A vocação cenográfica da iluminação pública no processo de valorização da pisagem urbana contemporânea. In: CONINTER - CONGRESSO INTERNACIONAL INTERDISCIPLINAR EM SOCIAIS E HUMANIDADES, 2. Belo Horizonte, de 8 a 11 de outubro de 2013. Anais... Belo Horizonte: ANINTER-SH; UFMG, 2013.

LUME ARQUITETURA. Destacando monumentos - critérios e cuidados que podem ajudar. São Paulo, ed. 05, dez. 2003/jan. 2004. Seção Ponto de Vista. Disponível em: <http://www.lumearquitetura.com.br/pdf/ ed05/ed_05_Ponto_Monumentos.pdf>.

MOISINHO FILHO, E. F. Patrimônio cultural e iluminação urbana: diretrizes de intervenção luminotécnica no centro histórico de São Cristóvão, Sergipe. 2010.333p. Dissertação (Mestrado em Arquitetura e Urbanismo) - Universidade Presbiteriana Mackenzie, São Paulo, SP, 2010.

NARBONI, R. A luz e a paisagem: criar paisagens nocturnas. Lisboa: Livros Horizonte, 2003. 
PHOENIX, Graham. Com a palavra o presidente da IALD. Lume Arquitetura, São Paulo, ed. 18, fev./mar. 2006. Entrevista concedida a Maria Clara de Maio. Disponível em: <http://www.lumearquitetura. com.br/pdf/ed18/ed_18_Entrevista.pdf $>$.

PORTAL BRASIL. Saiba quais bens brasileiros são Patrimônio Mundial Cultural. 2009. Disponível em: <http://www.brasil.gov.br/ cultura/2009/10/saiba-quais-bens-brasileiros-sao-patrimoniomundial-cultural>. Acesso em: 2016.

SANTOS, E. R. dos. A iluminação pública como elemento de composição da paisagem urbana. 2005. 109f. Dissertação (Mestrado em Arquitetura) - Universidade Federal do Rio Grande do Sul, Porto Alegre, RS, 2005.

SILVA, Mauri Luiz da. Iluminação: simplificando o projeto. Rio de Janeiro: Moderna, 2009. 172p.

SZABO, Ladislao. Sim à luz - considerações de Ladislao Szabo. Lume Arquitetura, São Paulo, n. 2, jun./jul. 2003. Entrevista concedida a Maria Clara de Maio. Disponível em: <http://www.lumearquitetura.com.br/ img/ed_02\%20En\%20-\%20Ladislao.pdf>. 